\title{
Strategic Planning in an Educational Development Centre: Motivation, Management, and Messiness
}

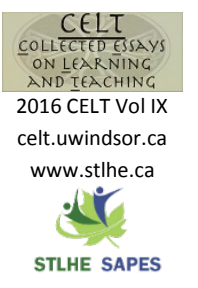

\section{Simon P. Albon, Isabeau Iqbal, and Marion L. Pearson University of British Columbia}

Strategic planning in universities is frequently positioned as vital for clarifying future directions, providing a coherent basis for decision-making, establishing priorities, and improving organizational performance. Models for successful strategic planning abound and often present the process as linear and straightforward. In this essay, we examine our own experiences of strategic planning for a new educational development centre situated in a Faculty of a research intensive university. Drawing from the literature, we provide a brief history of strategic planning in university contexts and consider criticisms and benefits. We investigate complicated issues related to our own process and, throughout, we argue that in spite of established formulas for creating a strategic plan, the process is non-linear and messy. We end this paper with recommendations for educational developer colleagues.

\section{Introduction}

f you don't know where you're going, any road will
take you there.

- Carroll, 1865

While in theory strategic planning is linear...development of a strategic plan is more analogous to conducting an orchestra.

- Hinton, 2012

The words "strategic planning" can elicit visceral responses: rolling eyes, sweating palms, and feelings of futility, to name a few. For some individuals working in higher education, strategic planning may be considered a distraction from our real work of teaching and research. The literature on strategic planning, however, positions this activity as vital for clarifying future directions, important for developing a coherent basis for decision-making, necessary for establishing priorities, and helpful at improving organizational performance (Shah, 2013). The literature also abounds with models for successful strategic planning that elaborate on the steps to follow. Often, these steps are presented as linear and relatively straightforward. Our own view is that strategic planning is complex, chaotic, and frequently detached from daily activities and decision-making (Mintzberg, 1994; Sevier, 2003).

This article is based on our experiences of developing a strategic plan for the teaching and learning centre in our Faculty. Having been involved in strategic planning previously but never leading the process, we presented some of these experiences at the round table sessions at the 2015 Society of Teaching and Learning in Higher Education Conference. The intent was to share with and learn from like-minded colleagues and more experienced strategic planners from other post-secondary institutions to build our understanding of strategic planning generally and our own processes specifically. In the current work, we 
argue that in spite of established formulas for creating a strategic plan, the process is non-linear and messy. We begin with a literature review highlighting those areas that have been particularly helpful for building our current understanding of strategic planning and for framing our planning efforts. Included is a brief history of strategic planning in universities and important criticisms and benefits of strategic planning. We then outline the stages of our own planning process and draw attention to elements of our academic background and culture that hindered or supported us. We emphasize the complexities of strategic planning and end by offering lessons learned and recommendations based on our understandings of what worked and what did not.

\section{History of Strategic Planning in Universities}

While strategic planning has its roots in the military, modern conceptions originated in the business practices of the early twentieth century (Sheridan, 1998; Taylor, 1911). Increasingly valued as a standard business management tool in the postWorld-War-II decades, strategic planning remained mostly a private sector undertaking until the late 1970s (Candy \& Gordon, 2011). The growing difficulties experienced in the university sector at that time helped shift the uneasy alliance between business and higher education. Initially, universities were reluctant to adopt business mindsets to address their challenges, and were resistant to calls of efficiencyminded reformers to run public institutions more like businesses (Hinton, 2012). Notions of product development, industry growth, market share, and risk management were foreign to university culture, and universities did not view themselves as serving customers. Complicating planning processes were issues related to university structure such as decentralized power, professional autonomy and tenure, loose coupling of multiple academic units, complex committee structures, and government intervention (Hardy, 1991). However, perspectives changed by the late 1980s. By then, strategic planning had emerged in universities as a potential solution for developing a proactive stance in environments of increasing competitiveness and fluctuating enrollments, changing student demographics, inconsistent funding and spiraling costs, and calls for greater accountability, including the rise of accreditation standards (Aleong, 2007).

While planning was not new to universities (Kotler \& Murphy, 1981; Sheridan, 1998), strategic planning was. Initial university strategic plans often focused on internal organizational issues, staffing, and resourcing, and produced documents that described the institution and its vision, mission, and value to society but contained limited or unrealistic goals for change (Cowburn, 2005). Created primarily by senior leadership within the institution interested in “orderly, systematic management" (Dooris, 2002, p. 27), these top-down plans often sat on the shelf and, in some cases, were done merely to appease external stakeholders, such as government funders, alumni, parents, and the general public (Carron, 2010; Chance, 2010). Often, strategic planning was a symbolic activity designed as a promotional tool for the university, but with limited acknowledgement of external pressures or plans for adapting to future challenges (Hinton, 2012). As de Haan (2014) states, "their use, in short, [was] more a rhetorical device than a practical template for action" (p. 137).

Throughout the 1990s, perspectives on strategic planning changed dramatically in academia as university leaders realized that in a rapidly globalizing and increasingly competitive world there was no longer a "status quo for a campus" (Wilkinson, Taylor, Peterson, \& de Lourdes Machado-Taylor, 2007 , p. 12). Instead, laying claim to institutional distinctiveness, finding a unique niche in the higher education marketplace, and being able to attract and keep the best students, faculty, and staff became critical for long-term viability (Aleong, 2007; Keller, 1999). However, despite great effort and improved efficiencies through technology, strategic planning left many universities fragmented, unable to cope effectively with societal change, responding reactively rather than proactively to challenges, and incapable of transforming how they functioned as educational institutions (Baer, Duin, \& Ramaley, 2008). Frequently, the gap between planning and 
implementation impeded meaningful change as the goal of strategic planning was about creating the plan rather than using it (Cowburn, 2005; de Haan, 2014; Sevier, 2003). Performance indicators focused on easily quantifiable factors, such as numbers of people (e.g., students and faculty) and budgets, rather than the quality of education provided or the student experience (Soutar \& McNeil, 1996). Criticisms mounted just as strategic planning was becoming common practice in higher education. As public support for post-secondary institutions eroded, strategic planning initiatives were "disparaged for being too linear, for relying too heavily on available hard information, for creating elaborate paperwork mills, for being too formalized and structured, for ignoring organizational context and culture, and for discouraging creative, positive change" (Dooris, 2002, p. 27). During this time period, however, university administrators and strategic planners began to recognize that strategic planning should take place not only at senior leadership levels but at all levels within the organization. As Carron (2010) points out, in universities "Every manager is a strategy maker and strategy implementer for the area which he/she has authority over and supervises" (p. 7). Indeed, Delprino (2013) suggests that senior administrators best serve the process by "leading from afar" (p. 25) and that a strategic plan needs to be created in collaboration with faculty, staff, and students.

Although criticisms of earlier strategic planning efforts have been ascribed to simplistic cause-and-effect thinking and mechanistic technicalrational approaches by university leadership (Chance, 2010), contemporary views have become more sophisticated about how strategic planning is defined and the limits of former theories and practices (Sevier, 2003; Sheridan, 1998). In the past decade, for example, there has been growing recognition of the complex and dynamic nature of university contexts and that unless strategic planners are prepared to adapt their plans as circumstances change, strategic plans are unlikely to have much effect in the short or long term (West, 2008). Although the stepwise linear approaches, such as issue-based approaches (e.g., McNamara, 2010; Mastrodonato, 2007) and goalsor vision-based approaches (e.g., Carron, 2010; Hinton, 2012), remain the dominant strategic planning tools in educational settings, Mintzberg (1994), Keller (1999), and Baer et al. (2008) suggest that road-map models are not well-suited for the rapidly changing environments in which universities operate today. Instead, they suggest modified approaches that embrace broader understandings of change and embody creativity, iteration, responsiveness, flexibility, and inclusiveness. Chance (2010) suggests that models incorporating decisionmaking spirals, design thinking, interactive learning, and improvisation are more applicable for contemporary strategic planning efforts.

While perspectives and approaches differ, Wilkinson et al. (2007), Carron (2010), and Hinton (2012) suggest three central concepts that are particularly important for university strategic planning exercises today. First, the approach taken should be used only as a guide. Institutions need to develop strategic planning processes that fit their unique needs and circumstances. As George Keller (1999), one of the seminal authors in university planning, attests, "There is no one way to do university planning" (p. 1). Second, broad-based involvement is critical for the success of the planning process. Determining which stakeholders to involve, and when and how they will contribute, requires careful consideration. Generating a sense of shared governance and ownership in the process is essential to sustaining the plan and change process. Finally, the congruence between planning and implementation is crucial. Continual evaluation and adjustment should be part of each step in the process. Revisiting previous steps not only promotes congruence but encourages flexibility and revision as new insights are uncovered. Strategic planning processes and plans that emphasize such purposeful "conscientious tailoring" (Chance, 2010 , p. 52) are felt to increase the likelihood of alignment between planning, action, and change.

Questions of whether strategic planning has had any impact on university performance are still debated (Chance, 2010; Mintzberg, 1994; Nauffal \& Nasser, 2012). Dooris, Kelley, and Trainer (2004) assert that "a convincing, generalizable empirical study on the efficacy of strategic planning in higher education has yet to be published" (p. 9). Despite historical shortcomings and the apparent lack of convincing evidence to date, strategic planning is now 
a standard tool for managing universities (Shah, 2013; Temple, 2003; West, 2008). Skepticism aside, Dooris et al. (2004) strongly suggest that the success of strategic planning is mostly process-related: done poorly, strategic planning is ineffective; done well, it can be a powerful tool to help universities thrive. Strategic planning efforts at Pennsylvania State University (Dooris, 2002), Eastern University (Aleong, 2007), the University of Minnesota (Baer et al., 2008) and the University of British Columbia (University of British Columbia, 1998) offer some insight into the positive impacts that strategic planning has had in university contexts. Significantly, the quality of teaching, learning spaces, and the student experience emerge in these examples as important indicators of improved institutional performance. Table 1 provides some of the benefits of strategic planning in universities gleaned from the literature.

\section{Our Context}

The strategic planning process discussed here was for the Office of Educational Support and Development (OESD) in the Faculty of Pharmaceutical Sciences at the University of British Columbia (UBC). ${ }^{1}$ The Faculty has been experiencing profound changes since 2011 (Faculty of Pharmaceutical Sciences, 2012): these changes have included a move into a new state-of-the-art building with more than five times the square-footage of its previous home; a complete turnover of the senior leadership, including two changes of the Associate Dean Academic due to

\section{Table 1}

Some benefits of strategic planning in university contexts

- providing a vision, road map, and focus for the institution's future; where it wants to go and the routes to get there;

- encouraging input and ideas from all parts of the organization on what can be done to ensure future success and eliminate potential barriers to that success; building ownership in the plan;

- recognizing opportunities as they emerge; being alert, responsive, and flexible to change;

- prioritizing the crucial strategic tasks necessary to actualize the institution's vision, and making decisions supported by context-specific evidence;

- coordinating the actions of diverse and separate parts of the organization to accomplish strategic tasks, thereby generating a sense of community within the university;

- allowing proactive allocation of resources available for growth and change to critical programs and activities;

- establishing measures of success so that progress of the organization can be evaluated; and,

- generating commitment to implement the plan by involving all parts of the organization and its people in the development, and fostering stakeholder participation and buy-in related to the plan development, implementation, and success.

\footnotetext{
${ }^{1}$ UBC is a global centre for research and teaching, comprises two campuses and 20 Faculties, employs over 15,000 faculty and staff, enrolls 60,000 students, and is consistently ranked among the 40 best universities in the world. The challenges of institutional-level strategic planning in university contexts such as this are particularly complex and emphasize the critical importance of well-established planning and implementation processes (Aleong, 2007; Hardy, 1991).
} 
retirements; a $25 \%$ growth in the faculty roster (to approximately 65); a nearly 50\% increase in undergraduate class size (to 224 per year); and curriculum revision of unprecedented scope. The Faculty is the fifth in the country to transition to offering an undergraduate Doctor of Pharmacy (PharmD) program in place of the Baccalaureate of Science in Pharmacy (BSc(Pharm)) program. Approaches vary, but at UBC this new program involves a revolution in curriculum structure (e.g., from discipline-specific courses to integrated diseasestate modules) and pedagogical practices (e.g., from traditional lectures to team-taught case-based approaches). Furthermore, this credential change has necessitated the creation of two additional programs: a bridging program for $\mathrm{BSc}$ (Pharm) graduates wishing to upgrade their education and a program to replace the Faculty's existing highly specialized twoyear postgraduate PharmD program.

The Faculty's OESD was established in 2009 and initially consisted of two part-time staff members providing support for program evaluation efforts and special projects of the Associate Dean Academic. The unit gradually grew, and in 2013, leadership of the OESD devolved to two faculty members (co-authors Simon Albon and Marion Pearson) who shared directorial duties while maintaining their existing teaching and service responsibilities and completing $\mathrm{PhD}$ degrees in Curriculum Studies. Early efforts of the new OESD leadership focused on formalizing the unit within the Faculty including reexamining key roles and responsibilities, revisiting existing OESD policies and practices, establishing supporting infrastructure, and stabilizing day-to-day operations. At the time of writing, the unit consisted of the two co-directors and five full-time and one part-time faculty and staff, four of whom were dedicated to the development of the new PharmD programs. Two staff positions were vacant, presenting both an impediment to the effective functioning of the unit and an opportunity to reconsider staffing needs.

As the support needs of the Faculty's educational programs evolved and individuals with new skills were recruited into the OESD, the functions of the OESD expanded to include the six areas illustrated in Figure 1.

These functions were not implemented equally. For example, student development initiatives were limited, while inordinate effort was being expended on administering Faculty- and universityrequired student evaluations of teaching as part of the program evaluation mandate of the unit. Providing the necessary faculty development to nurture new faculty members, transform deeply-rooted discipline-

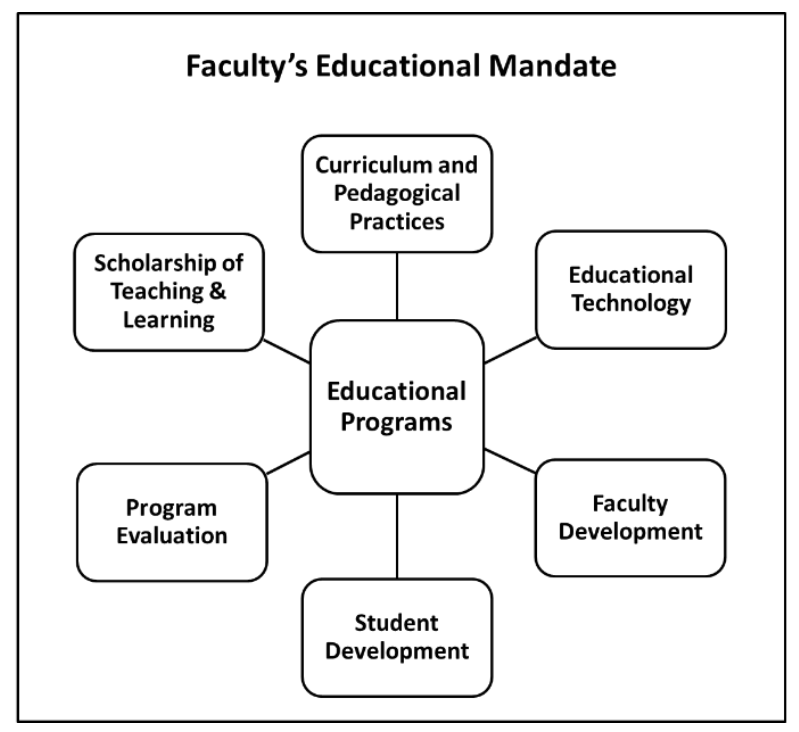

Figure 1

Educational support and development functions of the OESD 
based curricula and pedagogical practices of experienced faculty members, and advance the scholarship of teaching and learning presented many challenges.

In this environment of significant change in leadership and curricula, with the need for educational support exceeding capacity and a pressing opportunity to review staffing and long-term sustainability, the time was ripe for developing a strategic plan for the OESD. Accordingly, we embarked on this exercise, confident that the task would be straightforward if we applied our scholarly habits and prior strategic planning experiences and remained mindful of our limited expertise in strategic planning.

\section{Our Process}

Our process began in March 2013, shortly after the co-directors of the OESD had been appointed and a new staff member had been hired to replace one who had left. During three working meetings held over a period of two and a half months, OESD team members identified strategic functions (see Figure 1), created a mission statement, and articulated the unit's values. We also reviewed the Faculty's strategic plan (Faculty of Pharmaceutical Sciences, 2012) and the report from a comprehensive operations review of the OESD that had been completed in November 2012 to ensure our efforts were aligned with these documents. One staff member left and two new staff members joined the unit while this process was underway, slowing the pace of our progress. One of us (Isabeau Iqbal) facilitated the process, which involved explaining what our purpose and tasks were, defining terms, ${ }^{2}$ finding example strategic plans to share, taking notes, seeking clarification as necessary, and prompting group members to complete specified tasks between meetings. Hinton's (2012) model of strategic planning guided our process, albeit loosely. That is, we understood the need to define our mission and values, as this would help guide our work as a relatively new unit with several recent members, but had not mapped out how our work would develop into a strategic plan.

Having articulated our strategic functions, mission, and values, we agreed the next step would be to develop a vision statement (Hinton, 2012). Unfortunately, this step was only partially completed before the entire strategic planning process came to a standstill due to many urgent and competing priorities, including teaching commitments, completing $\mathrm{PhD}$ dissertations in the case of the OESD directors, and establishing a new system of compulsory program evaluation activities related to student and course evaluations and peer reviews of teaching. After a hiatus of just over one year, we restarted the process in June 2014. In the interim, there had been additional turnover of OESD staff, the Faculty had hired a new Dean, an active search for a new Associate Dean Academic was underway, and planning for the new undergraduate PharmD curriculum was progressing rapidly. Somewhat discouraged by our lack of strategic planning progress, we felt the need to reexamine and articulate the unit's role more clearly within the context of a Faculty undergoing substantial change.

At an OESD team meeting, we made the following decisions that we believed would help us complete the strategic plan in a timely manner:

- We would approach this activity with the intention of producing a living document, a plan that would be revised and updated regularly. This, we thought, would take the pressure off feeling that we had one chance to get the plan right. Furthermore, regular review of the plan would allow us to assess our implementation and re-plan as necessary, two steps that are considered important in successful planning processes (Chance, 2010; Shah, 2013; West, 2008).

- Our plan would encompass a period of only one year. Given the rapid rate of change in the Faculty, and anticipating that the unit might undergo structural and functional

\footnotetext{
${ }^{2}$ Sevier (2003, p. 19) claims that "often colleges and universities jump into a strategic planning process without taking the time to define key terms." In our case, we spent little time early on discussing language, being more interested in the practicalities of the process. The definitions that we adopted are outlined in Appendix 1.
} 
changes at the behest of the incoming Associate Dean Academic, we felt we could not set longer term goals for the unit. Though we recognized that sustainable plans need to acknowledge, understand, and manage uncertainty (Baer et al., 2008; Shah, 2013; Walker, Hassnoot, \& Kwakkel, 2013), we nevertheless chose the one-year timeline.

- October 2014 would be the target completion date for the plan.

- We would dedicate in-person time every two weeks to work on the plan because we felt this would help us maintain our momentum in completing our tasks, which would require time and hard work, and that we would be learning by doing (Chance, 2010; Hinton, 2012; Wilkinson et al., 2007).

- We would adopt the strategic functions, mission, values, and vision drafted a year earlier.

- A subgroup of the OESD members would undertake the strategic planning process and consult with the other members as needed. We were aware that the planning committee should, ideally, consist of the entire OESD team plus external stakeholders such as students, faculty, and senior administrators (Delprino, 2013; Hinton, 2012; Wilkinson et al., 2007), but made a decision to include only selected OESD members to begin. This decision was justified by the fact that the entire OESD team had contributed to the articulation of the strategic functions, mission, values, and vision, and we had a strong sense of key stakeholders' opinions from the survey and interviews that had been conducted during the 2012 operations review. We also felt we might be able to make more rapid progress with a small, dedicated group.

- One of us (Isabeau Iqbal) would take the lead in designing and facilitating the process, keeping records, sending out meeting notes, and prompting members as needed to complete action items.
- We would report on OESD activities to the Faculty at every opportunity, including through our newsletter and at Faculty-wide meetings. In addition, we would establish weekly meetings with the Associate Dean Academic, develop How-To documents to capture and share our processes, and disseminate our work in scholarly publications and presentations whenever possible. Despite not having a completed strategic plan, we felt many of our current activities would remain part of the final strategic plan we produced. Bridging the gap between planning and implementation early in our process was deemed critical for the long-term sustainability and success of our strategic planning efforts and the OESD (Carron, 2010; Hinton, 2012; Wilkinson et al. 2007).

We also started to solicit ideas and plans from other educational developers via relevant listservs (e.g., the Educational Developers Caucus listserv) and conversations with other teaching and learning centre directors who had undertaken similar processes, and began to consider writing a paper and/or presenting our experiences at a conference. Taking a more scholarly approach to our subsequent work also emerged in our discussions (see Recommendation 1 below). And thus we began. Below, we provide a timeline of our activities and reflective comments about what transpired:

\section{June 2014}

We identified strengths, opportunities, aspirations, and results via a process/framework called SOAR that applies an appreciative inquiry approach to strategic planning (Stavros \& Hinrich, 2009). SOAR is an alternative to the more common SWOT analysis (Kotler \& Murphy, 1981). SOAR's focus is on enhancing what is currently done well, as opposed to concentrating on perceived threats and/or weaknesses. The basic questions to be answered via SOAR are (Stravros, Cooperrider, \& Kelley, 2003):

- What are our greatest strengths?

- What are our best opportunities?

- What is our preferred future? 
- What are the measurable results that will inform us that we have achieved our vision of the future?

Individually, we brainstormed responses to the above questions and then shared our thoughts. We identified themes, noting commonalities and differences. Detailed notes were taken and individual members were asked to review and reflect upon the results of this activity prior to the next meeting.

July 2014

We reviewed and discussed SOAR results and began to articulate overarching goals based on these. Realizing that at current levels of resourcing we could not achieve everything we desired, we eliminated some of the ideas that had been generated. Most notably, we removed the goal of providing study-skill support for students. Four key goals ultimately emerged from this process: 1) curriculum and pedagogical practices, 2) faculty development, 3) program evaluation, and 4) the scholarship of teaching and learning. Focusing our efforts in these four areas would support our mission and help us achieve our vision (Carron, 2010; Hinton, 2012; Wilkinson et al. 2007), and would align with most of our previously determined strategic functions (Figure $1)$.

\section{August 2014}

We struggled with committing time to the process as there were members on vacation and other urgent and important tasks that took priority over the seemingly non-urgent yet important strategic planning initiative. Competing tasks included preparations for teaching in the new academic year, curriculum development activities related to our new PharmD program, faculty development workshop preparation for the fall including our Celebrate Learning Week event (University of British Columbia, 2014), and administration of student and course evaluations and peer reviews of teaching for the academic year.

\section{September 2014}

With some momentum having been lost, we began the academic year by revisiting the four key goals we had previously identified. Our process, to this point, was largely guided by information found freely on the internet (e.g., short guides to strategic planning, blog posts, internet articles among them Garber (2006), Hinton (2012), Mastrodonato (2007), and McNamara (2010). Based on some strategic plans that had been shared with us, we determined that our next steps should be to brainstorm objectives and action items for the four key goals we had identified in July. It was at this point we realized the extent of the variability in usage of strategic planning terms; the result, for us, was confusion. We disagreed with Wilkinson et al. (2007) and Sevier (2003) who opined that terminology was irrelevant and felt, to the contrary, that it was essential to gain some understanding of what was meant by words such as "goals," "objectives," and "strategies." Therefore, we spent time examining "troublesome terms" (Hinton, 2012, p. 33) and agreeing on the terminology we would adopt; in particular, we clarified the definitions of a goal, an objective, and an action item. Recommendation 2 below provides further thoughts about the language of strategic planning and Appendix 1 lists our adopted terms and definitions. Then, we divided the goals among ourselves and worked individually to articulate objectives for each goal and the activities required to achieve them.

\section{October 2014}

We shared our work electronically, and commented on each other's draft goals, objectives, and action items. We then met and discussed our work during two face-to-face meetings in October. The process 
continued to be very messy and complex at this stage as we struggled to agree on appropriate goals, objectives, and action items. During our two collaborative discussion/writing sessions, we not only modified our original goals, but revisited questions such as: "How broad or narrow should these items be?" "How aspirational should we be?" "How much detail should we provide?" and "Do these goals actually align with our strategic functions?" We were living Chance's (2010) descriptions of strategic planning as an iterative process during which members wrestle with issues and collect evidence to help address them. It became increasingly clear that our planned submission date of October would not be met. At this stage a sense of paralysis infused our process as we struggled with the growing complexity of our situation and the multitude of paths available to us (Sull \& Eisenhardt, 2012).

\section{November and December 2014}

Despite our intention to dedicate time to our plan, planning efforts were abandoned for more urgent OESD responsibilities and we were unable to make any progress.

\section{January and February 2015}

Though we planned to meet and finalize our goals, objectives, and action plans, this did not happen. Instead, the OESD co-directors decided to work on the plan together to attempt to expedite the process. The intent was to circulate a solid draft to OESD members for comment once this step was done. Due to competing tasks, no further work was done on the strategic plan.

\section{March and April 2015}

Addressing frustration with our lack of progress on this task and sensing pressure from the Faculty's senior management team (i.e., the Dean and
Associate Deans) regarding the role and value of the OESD, one of the directors (co-author Simon Albon) completed a draft strategic plan. The plan included sections on: background; key audiences and stakeholders; mission, values, and vision; goals, objectives, and action items; progress to date; and existing stresses and future challenges. In addition, a plan for reorganization of the unit and associated budgeting was proposed. The draft plan was then forwarded to the other director for the next round of edits.

\section{May 2015}

The plan was edited (by co-author Marion Pearson) and readied for circulation to OESD members for what we felt would be a final round of edits. Instead, at the request of our newly appointed Associate Dean Academic, the plan went directly to the senior management team for review.

\section{Current Status of the Plan and its Implementation}

The draft OESD strategic plan has now been critically reviewed by the Faculty's senior management team and has been endorsed subject to revision. While there is clear support for the unit, the struggle continues to finalize the plan by the new target date of the end of the year. Questions have arisen regarding alignment between OESD's strategic functions and its mission, vision, goals, and actions. Decisions regarding strategic focus seem in continuous flux, resourcing for the unit is ambiguous and remains in the hands of senior management, and the availability of personnel to implement action plans in areas such as faculty development is very limited. The dynamic nature of our environment and a willingness to plan with uncertainty continue to characterize our strategic planning efforts (Aleong, 2007; Hardy, 1991; Hinton, 2012; Walker et al., 2013). Despite these obstacles we believe strongly in 
the importance and value of the work of the OESD in supporting the Faculty's educational mandate and continue to implement and report on many aspects of the draft plan. Appendix 2 provides some of the OESD activities derived from our strategic planning efforts to date. In the next section of this article we present some additional lessons learned and recommendations to complement those referenced earlier.

\section{Lessons Learned and}

\section{Recommendations}

Based on our experiences and drawing from the literature, we offer the following recommendations for a successful strategic planning process.

\section{Take a scholarly approach}

Inform your strategic planning practices and processes with the scholarly literature. Taking an evidenced-based approach is something commonly espoused in educational development (Professional and Organizational Development Network, 2016) and other areas such as scholarly teaching and the scholarship of teaching and learning (Pearson \& Albon, 2013). Yet, in our case, we did not uphold this principle until we were well into the strategic planning process. Earlier engagement with the literature would have provided a better grounding for our process and helped us proceed with more awareness and appreciation of inherent challenges. Venturing into the vast body of strategic planning literature, however, can be daunting for non-experts. Making sense of this field continues to test our sense of competence. While perspectives on strategic planning seem to share international appeal and commonalities (Chance, 2010; Cowburn, 2005; Dooris, 2002; Shah, 2013), much of the scholarship relates to institution-level strategic planning efforts in universities. There is scant focus on small Facultylevel teaching and learning centres like the OESD and little description of the actual experiences of strategic planners. For those interested in entering into the strategic planning literature, we recommend starting with broad overviews of the literature and historical development of the field (Dooris, 2002; Sheridan, 1998) and then moving into the practical guides (Carron, 2010; Hinton, 2012; Wilkinson et al., 2007). As mentioned previously, we started with Hinton's (2012) guide as well as other internet resources before further exploring the literature. We believe the references cited in this article provide a solid entry point for novice strategic planners. Recent work by the Educational Development Unit at the Taylor Institute (Taylor Institute for Teaching and Learning, 2015) offers a critical examination of their process and may be a useful resource. We also found it helpful to consult the strategic plans of our colleagues at other centres, many of whom readily sent us copies of their plans and were happy to share their experiences and answer our questions. As we have attempted to show, the literature is helpful for situating strategic planning in educational contexts, providing a common language, and orienting planners to the complexities and nuances of the process. We would also encourage colleagues to document and write about their process in order to contribute to the strategic planning literature which is lacking in documenting the experience of small learning and teaching centres.

\section{Agree upon terminology}

The language used in strategic planning can be unclear and there may be multiple definitions and inconsistent usage of a given term. For example, "strategy" and "strategic planning" are used as both nouns and verbs and/or substituted for one another, leaving interpretation to the reader (de Haan, 2014). Another example is the definition and use of the words "mission" and "vision," two common components of contemporary strategic plans. Garber (2006) defines "vision" as "a picture of the future state of the organization" (p. 2) and "mission" as "the means for achieving the vision" (p.2). Hinton (2012) provides a similar definition of "vision," but defines "mission" as a statement delineating "why the institution exists and what its operations are intended 
to achieve" (p. 9). There are also inconsistencies in the way authors treat the words "goals" and "objectives" in strategic planning (Hinton, 2012; Wilkinson et al., 2007).

In our case, particularly the early stages, we spent almost no time discussing language. Thinking that we already knew what words meant, we were more interested in the pragmatics of the process than debates over definitions. In retrospect, we should have spent more time establishing a common understanding of planning terminology. We recognize now that having clarity about what key words mean and how they will be used to frame and streamline the strategic planning process is immensely helpful; getting everyone on the same page through the use of common language is a crucial and often underappreciated step (Hinton, 2012). We were well into our process before we drew on the wisdom of our scholarly colleagues and adopted the definitions provided in Appendix 1. Based on our experience, we believe it is helpful for those involved in strategic planning to discuss and agree upon what terms will be adopted, their definitions, and how they will be used.

\section{Accept and work with the reflexive and iterative aspects of planning}

Much of the literature portrays strategic planning as a linear, stepwise process. Our own process was often slow and fragmented and did not progress smoothly from start to finish. Though the slowness of pace was frustrating, the process prompted us to reflect deeply on our work and respond to our changing environment. In addition to experiencing first-hand the dynamic nature of university environments (at least in our Faculty), we embodied Chance's (2010) notion of "conscientious tailoring" (p. 52). Had we been more accepting of the iterative, reflexive aspects of strategic planning, we might have felt more positive about our progress.

\section{Maintain momentum by being time- bound}

With so many competing priorities, it was difficult to devote sufficient attention to the strategic plan on an ongoing basis and over an extended period of time. We would suggest setting a short, but realistic, period of time to complete the strategic plan. It might be useful to work in an intense fashion over a limited number of days to build and maintain momentum and then gain a sense of accomplishment. Hinton (2012) offers some sage advice regarding timing and the planning cycle. She suggests there is a tendency among strategic planners to front load the planning process "because enthusiasm is high and everyone would like to see the plan successfully completed" (p. 11) and proposes a phased approach to spread out the work of strategic planning in a way that meets individual needs and circumstances. If one adopts this approach, it is important to build in scheduled opportunities to reflect on contextual changes and how they might influence the plan and its implementation over time (Hinton, 2012).

\section{Hire a facilitator}

We self-facilitated the process and, in retrospect, we think that we would have benefited from a facilitator to guide us, complement our knowledge and experience, and help ensure the plan was completed within the expected timeframe. Facilitators play an impartial role in helping groups function effectively; they proceed without decision-making authority by assisting groups identify and solve their own problems (International Association of Facilitators, 2015). Hinton (2012) notes that engaging an external facilitator can help balance competing voices and also allows everyone involved in the planning team to contribute at meetings. The involvement of a facilitator assumes, of course, that members will cooperate with one another and the facilitator to reach their goals. It also assumes that resources are available to hire a facilitator, which was not the case for us.

\section{Identify Faculty needs}

In the fall of 2012, a thorough operations review of the OESD was conducted by an external consultant. 
The detailed report, which outlined areas of strength, challenge, and improvement for the future of the unit, served as an important resource as we started our strategic planning process. We also drew from our academic experiences and institutional history. In addition, the OESD directors consulted with other Faculty colleagues for their input and insights into how the OESD might serve the Faculty. These steps constituted our environmental scan, a step commonly recommended in the literature (e.g., Hinton, 2012; Kotler \& Murphy, 1981; Wilkinson et al., 2007). An environmental scan such as this provides planners with a common understanding of trends, and information on whether members of an organization have a unified view of the future and the resources they have or will need as planning proceeds. The scan can be used to inform the organization's vision and identify the broad strategic goals and objectives that will guide an action plan. We agree, however, with Wilkinson et al. (2007), who state that "everyone is, in fact a scanner" and, that if these "casual and informal individual efforts are formalized and documented" (p. 18) then an ongoing scanning process is in place and supports the notion of strategic planning as an iterative process.

\section{Engage stakeholders, especially senior administrators}

Think carefully about your stakeholders and how to involve them in the process; provide multiple opportunities for them to own the vision and the plan through their participation and input (Delprino, 2013; Hinton, 2012). Inclusion becomes as important as the process itself for creating long-term buy-in and commitment to future change. This is particularly so for senior administrators. The lore at this university suggests, and we agree, that to achieve our educational mandates we require full support from those who are two academic ranks above us; in our case, that means the Associate Dean Academic and the Dean. Involve them early in the process, gather their ideas, and have them review drafts; organize open forums and discussion groups in which they participate and encourage them to openly support and advocate for the plan and its implementation. This application of the notion of "managing up" has proven successful in other university contexts (Gunsalus, 2006; Nauffal \& Nasser, 2012).

\section{Align planning and implementation}

Experienced strategic planners such as Carron (2010), Hinton (2012), and Wilkinson et al. (2007) espouse the importance of congruence between planning and implementation. Early challenges of strategic planning in universities have been attributed to the gap between the two (Chance, 2010; Cowburn, 2005; de Haan, 2014). However, contrary to Hinton (2012) and others (e.g., West, 2008) our planning process did not include development of an implementation plan and readers will notice these words do not appear in Appendix 1. While this omission would be critical for institutional-level strategic planning efforts (Carron, 2010), in our context, a small unit embedded in a Faculty, we were both planners and implementers and responsible for both. Translating many aspects of our plan (as it existed) into front-line activities, such as developing and administering the teaching evaluation and peer review of teaching processes, was often a matter of common sense required to meet established university and Faculty policies (Sevier, 2003). We put more importance on how to communicate our activities and progress to the Faculty. In this regard, developing key performance indicators earlier on in our process would have helped our implementation process considerably (Wilkinson et al., 2007). While the language of performance measures was not part of our strategic planning discussions (the words performance indicator do not appear in Appendix 1), we did establish mechanisms for evaluating our successes (e.g., communicating through our newsletter and at Faculty-wide meetings, establishing weekly meetings with the Associate Dean Academic, developing How-To documents, and disseminating our work in scholarly publications and presentations). Criteria for evaluating the long term impact of our strategic planning efforts such as measurable improvements in curriculum and pedagogical practices in our undergraduate programs, career 
growth for faculty, student satisfaction with their learning experiences, and our capacity for educational scholarship and the scholarship of teaching and learning would have further improved the alignment between planning, our implementation activities, and the plan's vision. Knowing what we do now, we would highly recommend that those embarking on a strategic planning journey seriously consider the implications of implementation planning and the development of performance indicators to establish their successes. As Hinton (2012) says, "the implementation plan delves into the messy work of getting the job done" (p. 12). In our opinion, being able to celebrate your successes energizes the process.

\section{Conclusions}

Strategic planning has emerged as an important management tool in university contexts. For educational development centres, in particular, strategic planning is a potentially valuable activity as the process can help communicate the unit's value to the institution, establish priorities, and clarify future directions. However, the potential also exists for strategic planning to be a drawn-out, top-down activity that results in little more than a neglected document. In order to avoid this outcome, newer models of strategic planning emphasize the iterative nature of planning, put emphasis on inclusive processes that involve multiple stakeholders, and promote coherence between planning and implementation. Approaches to planning recognize that, though multiple models for planning exist, those involved in the process will adapt them to their needs. Our own experience of planning has been messy and chaotic, but, perhaps strangely, has also been insightful and positive. We have learned a great deal and been humbled at the same time. As individuals who are new to leading strategic planning, our entry into the literature and associated language was particularly challenging. While we are scholars in our respective academic areas, we had difficulty grasping the disciplinary assumptions, values and meanings implied by the authors we were reading (Green, 2010); our lack of clarity regarding concepts and language impeded our progress. Our first two recommendations address these issues and we wholeheartedly suggest that novice strategic planners take the time to familiarize themselves with the literature and establish and define the set of terms that will be used for their processes. Understanding the history of strategic planning in universities can also be helpful for situating your strategic planning efforts in the broader developments in the field while accessing the practical guides provides a place to begin framing the planning process. We have now decided that our future planning efforts will include an academic expert, at least in a consultative capacity.

We also did not at first appreciate the iterative nature of strategic planning or the extent to which the dynamics can impact the process and its duration. Naively, perhaps, we thought our past experiences and institutional history might suffice to complete the process in a timely fashion. On reflection, we realize that while our planning process was messy and took longer than we hoped or expected, our path was an important one. Though frustrating, the time it took helped us clarify how a new unit like the OESD could best support the Faculty and what we might reasonably do given current levels of resourcing in a period of intense change. Thankfully, our process also helped us more fully understand that we could not be everything to everyone and what our strategic areas should be (Hinton, 2012). Recommendations three and four attempt to address these issues and for newcomers to strategic planning we suggest they consider accepting the iterative and reflexive nature of strategic planning early in their process.

Recommendations five through seven relate to the pragmatics of the process. Hiring a facilitator, environmental scanning, and creating inclusive stakeholder engagement that includes senior management, are all recognized as important aspects of successful approaches to strategic planning. Although some may be more budget-related than others, strategic planners are encouraged to explore these mechanisms to help expedite their processes, clarify internal and external contextual pressures impacting the planning process, and improve buy-in and commitment to the plan's vision and action plan for change (Hinton, 2012; Wilkinson et al., 2007). 
Congruence between planning and implementation as described in recommendation eight is particularly important in contemporary approaches to strategic planning (Chance, 2010; Hinton, 2012). While our planning process did not sufficiently focus on this aspect, we did establish short-term mechanisms for evaluating our progress. Communicating our intentions and activities, for example in our newsletters and at Faculty meetings, became important aspects of our implementation activities. We also recognized that developing key performance indicators earlier on in our process would have considerably helped our implementation plan. Strategic planners, particularly those new to the process, are encouraged to include implementation planning and the development of measurable shortand long-term performance indicators as a central component of planning. You may find, as we did, that being able to show progress and celebrate successes can reinforce the strengths of your process and provide a welcome sense of accomplishment among team members.

While we believe this paper is an accurate reflection of our strategic planning experiences, it is not meant to be comprehensive. There are many areas highlighted in the literature that have not been discussed and could be considered a limitation of the case we present. One of them is budget and resourcing. Although Hinton (2012) insists that "the ultimate purpose of strategic planning is to drive resource allocation" (p. 12), in our case we had none, or at least no operating budget. We spent little time thinking about it, knowing the situation was not likely to change, and sympathize with those in similar situations. The literature cited in this article provides an avenue for exploring this issue in more detail (Wilkinson et al., 2007). We also recognize that the case we describe may be context-specific and relevant only to our Faculty. To address this issue we have attempted to provide enough detail to allow readers to decide for themselves how applicable our experiences are to their own (Stake, 2010). Like the strategic planners that supported us along the way, we are more than happy to share our experiences further with those who are interested. As we now appreciate, strategic planning is complex and time-consuming, and strategic plans do not write or implement themselves. The process can be fun and energizing, but it can also be tough going. Accept the challenges, reach out to the literature and more experienced colleagues, celebrate your successes, and, above all, be kind to yourself throughout.

\section{References}

Aleong, C. (2007). An empirical and qualitative study of the strategic planning process of a higher education institution. Journal of College Teaching and Learning, 4(4), 33-44. http://dx.doi.org/10.19030/tlc.v4i4.1614 VIEW ITEM

Baer, L. L., Duin, A. H., \& Ramaley, J. A. (2008). Smart change. Planning for Higher Education, 36(2), 5-16.

Candy, V., \& Gordon, J. (2011). The historical development of strategic planning theories. International Journal of Management \& Information Systems, 15(4), 71-89. http://dx.doi.org/10.19030/ijmis.v15i4.580 3 VIEW ITEM

Carroll, L. (1865). Alice's Adventures in Wonderland. London, UK: Macmillan.

Carron, G. (2010). Strategic planning: Concept and rationale. Delacroix, Paris: International Institute for Educational Planning. http://unesdoc.unesco.org/images/0018/00 1897/189757e.pdf VIEW ITEM

Chance, S. (2010). Strategic by design: Iterative approaches to educational planning. Planning for Higher Education, 38(2), 40-54.

Cowburn, S. (2005). Strategic planning in higher education: Fact or fiction? Perspectives: Policy and Practice in Higher Education, 9(4), 103109. http://dx.doi.org/doi:10.1080/136031 00500357324 VIEW ITEM 
de Haan, H. H. (2014). Where is the gap between internationalisation strategic planning and its implementation? A study of 16 Dutch universities' internationalisation plans. Tertiary Education and Management, 20(2), 135-150. http://dx.doi.org/doi:10.1080/13 583883.2014.896407 VIEW ITEM

Delprino, R. (2013). The human side of the strategic planning process in higher education. Ann Arbor, MI: Society for College and University Planning.

Dooris, M. J. (2002). Two decades of strategic planning. Planning for Higher Education, 31(2), 26-32. Retrieved from http://www.op ia.psu.edu/sites/default/files/twodecades.pdf VIEW ITEM

Dooris, M. J., Kelley, J. M., \& Trainer, J. F. (2004). Strategic planning in higher education. New Directions for Institutional Research, 123, 511. http://dx.doi.org/doi:10.1002/ir.115 VIEW ITEM

Faculty of Pharmaceutical Sciences (2012). 20122017 strategic plan: Pharmacy leadership through leadership and engagement. Office of the Dean, Faculty of Pharmaceutical Sciences, University of British Columbia, Vancouver, BC.

Garber, N. (2006). Strategic planning model and terminology. Retrieved from http://garbercon sulting.com/Strategic_Planning_Model.pdf VIEW ITEM

Green, D. A. (2010). Words fail us: How academics view language and ideas in higher education research. International Journal for Academic Development, 15(1), 47-59.

Gunsalus, C. K. (2006). The college administrator's survival guide. Cambridge, MA: Harvard University Press.
Hardy, C. (1991). Configuration and Strategy Making in Universities: Broadening the Scope. The Journal of Higher Education, 6(4), 363-393.

Hinton, K. (2012). A practical guide to strategic planning in higher education. Ann Arbor, MI: Society for College and University Planning. http://oira.cortland.edu/webpage/planninga ndassessmentresources/planningresources/S CPGuideonPlanning.pdf VIEW ITEM

International Association of Facilitators (2015). Statement of values and code of ethics. https://www.iaf-world.org/site/professional/ iaf-code-of-ethics VIEW ITEM

Keller, G. (1999). The emerging third stage in higher education. Planning for Higher Education, 28(2), 1-7.

Kotler, P., \& Murphy, P. E. (1981). Strategic planning for higher education. The Journal of Higher Education, 52(5), 470-489. http://dx.doi.org/10.2307/1981836 VIEW ITEM

Mastrodonato, P. (2007). Developing a strategic plan for your organization $-A$ road map for the future. Retrieved from https://www.coursehe ro.com/file/8475932/OutlineBasic-Strategic -Planning-1/ VIEW ITEM

McNamara, C. (2010). Should I use goals-based or issues-based planning? Retrieved from http://managementhelp.org/blogs/strategicplanning/2010/05/17/should-i-use-goals-ba sed-or-issues-based-planning/ VIEW ITEM

Mintzberg, H. (1994). The rise and fall of strategic planning: Reconceiving roles of planning, plans and planners. New York, NY: The Free Press.

Nauffal, D. I., \& Nasser, R. N. (2012). Strategic planning at two levels: Contrasting strategic planning processes at Qatar University (public) and Lebanese American University 
(private). Planning for Higher Education, 40(4), 32-39.

Pearson, M. L., \& Albon, S. P. (2013). Continuing the discussion on scholarship in pharmacy education. American Journal of Pharmaceutical Education, 77(2), article 38. Retrieved from http://www.ajpe.org/doi/ full/10.5688/ajpe77238 VIEW ITEM

Professional and Organizational Development Network in Higher Education (2016). Strategic plan/mission. http://podnetwork.org /about-us/mission/ VIEW ITEM

Sevier, R. A. (2003). From strategy to action. University Business, 6(2), 18-19.

Shah, M. (2013). Renewing strategic planning in universities at a time of uncertainty. Perspectives: Policy and Practice in Higher Education, 17(1), 24-29. http://dx.doi.org/1 0.1080/13603108.2012.679753 VIEW ITEM

Sheridan, D. H. (1998). An analysis of strategic planning practices at Ontario colleges of applied arts and technology (Doctoral dissertation). Retrieved from http://www.nlc-bnc.ca/obj/s 4/f2/dsk2/ftp02/NQ35419.pdf VIEW ITEM

Soutar, G., \& McNeil, M. (1996). Measuring service quality in a tertiary institution. Journal of Educational Administration, 34(1), 72-82.

Stake, R. E. (2010). Qualitative research: Studying how things work. New York, NY: The Guilford Press.

Stavros, J., Cooperrider, D., \& Kelley, D. L. (2003). Strategic inquiry, appreciative intent: Inspiration to SOAR. Retrieved from http://design-n.oit.umn.edu/about/intranet/ documents/Strategic_Inquiry_Appreciative_ Intent.pdf VIEW ITEM
Stavros, J., \& Hinrich, G. (2009). The thin book of SOAR: Building strengths-based strategy. Bend, OR: Think Book Publishing Co.

Sull, D., \& Eisenhardt, K. M. (2012). Simple rules for a complex world. Harvard Business Review, 90(9), 69-74.

Taylor, F. W. (1911). The principles of scientific management. Retrieved from http://www.ma rxists.org/reference/subject/economics/taylo r/principles/index.htm VIEW ITEM

Taylor Institute for Teaching and Learning. (2015). The portfolio approach to strategic planning. [STLHE conference handout]. University of Calgary, Calgary, AB.

Temple, P. (2003). Building strategy. Perspectives: Policy and Practice in Higher Education, 7(4), 91-92.

University of British Columbia (1998). Trek 2000: A Vision for the 21st Century. Retrieved from http://news.ubc.ca/1998/11/20/archive-me dia-releases-1998-mr-98-124/ VIEW ITEM

University of British Columbia. (2014). Celebrate Learning Week 2014. Retrieved from http://c elebratelearning.ubc.ca/events/past-events/2 014-events/VIEW ITEM

Walker, W. E., Haasnoot, M., \& Kwakkel, J. H. (2013). Adapt or perish: a review of planning approaches for adaptation under deep uncertainty. Sustainability, 5(3), 955-979. Retrieved from http://www.mdpi.com/2071 $-1050 / 5 / 3 / 955 / h t m$ VIEW ITEM

West, A. (2008). Being strategic in HE management. Perspectives: Policy and Practice in Higher Education, 12(3), 73-77. http://dx.doi.org/ 10.1080/13603100802181133 VIEW ITEM

Wilkinson, R. B., Taylor, J., Peterson, A., \& de Lourdes Machado-Taylor, M. (2007). A 
practical guide to strategic enrollment management planning. Virginia Beach, VA: Education Policy Institute. Retrieved from http://www.educationalpolicy.org/pdf/SEM \%20Guide.pdf VIEW ITEM

\section{Biographies}

Simon Albon, $\mathrm{PhD}$, is a Professor of Teaching in the UBC Faculty of Pharmaceutical Science. He currently teaches medicinal chemistry in the entry-topractice program and has research interests in the scholarship of teaching and learning. Simon is an award winning teacher and the Director of the Faculty's Office of Educational Support and Development.

Isabeau Iqbal, $\mathrm{PhD}$, is an educational developer in the Centre for Teaching, Learning and Technology at the University of British Columbia. There she is involved in various initiatives that include process design and facilitation, course design, and program planning and evaluation. Her research interests center on sociological aspects of teaching and higher education. Isabeau's $\mathrm{PhD}$ studies focussed on summative peer review of teaching and academic cultures.

Marion Pearson, $\mathrm{PhD}$, is a Professor of Teaching in the UBC Faculty of Pharmaceutical Sciences, where she currently serves as Director of Entry-to-Practice Programs in the Office of Educational Support and Development. She is also Associate Director, Innovation and Scholarship in the Centre for Health Education in the Faculty of Medicine. She has been a pedagogical innovator and has received the Killam Teaching Prize. Her research interests include student and faculty perspectives of curricular integration. 


\section{Appendix 1 \\ Definitions adopted for our strategic planning process and the authors that influenced them}

- Actions: are specific activities developed to accomplish the objectives and strategic goals; provide details on accountability, completion deadlines, resources required for completion, and how each action will be assessed and evaluated (Sevier, 2003).

- Goals: are a series of statements articulating the broad strategic initiatives needed to achieve the organization's vision (Nauffal \& Nasser, 2012; Wilkinson et al., 2007).

- Mission: is a concise statement delineating why the organization exists and its reason for being; describes the here-and-now for the organization and what it is here to do (Hinton, 2012; Kotler \& Murphy, 1981; Wilkinson et al., 2007)

- Objectives: translate broad strategic goals into a series of precise, measurable statements articulating the steps and processes necessary to achieve the strategic goals and realize the organization's vision; should be achievable within the period covered by the strategic plan (Carron, 2010; Hinton, 2012; Nauffal \& Nasser, 2012; Wilkinson et al., 2007).

- Strategic planning: is a dynamic process that establishes where an organization is going and how it will get there; is sensitive to changing internal and external environments and the decisions required to maintain strategic fit within this context; sets in motion a plan of action that provides direction for the organization and, through a common understanding of the mission, vision, values, and broad strategic goals, provides a congruent framework of objectives and actions that move the organization toward its envisioned future; creates a strategic plan that bridges the gap between institutional mission and vision (Carron, 2010; Hinton, 2012; Kotler \& Murphy, 1981; Mastrodonato, 2007; Shah, 2012; Wilkinson et al., 2007).

- Strategy: addresses a problem that the institution faces or an opportunity it wishes to take advantage of; implies big-picture thinking and a plan of action; is best used to set direction, focus efforts, encourage consistency of effort over time, and promote flexibility (Chance, 2010; Mintzberg, 1994; West, 2008).

- Values: represent a list of ideals and behaviors that individuals working in the organization believe are important for how they do their work (Hinton, 2012; Nauffal \& Nasser, 2012; Wilkinson et al., 2007)

- Vision: is a concise statement that articulates where the organization wants to be in the future; clearly expresses what the organization could and should become (Hinton, 2012; Wilkinson et al., 2007). 


\section{Appendix 2 \\ Some OESD activities during the 2014-2015 academic year}

1) Curriculum and pedagogical practices (i.e., learning-centred approaches to curriculum design and teaching practices; assessment of learning)

- Provided project management support to the BSc(Pharm), PharmD, and Flexible PharmD programs

- Led the development of assessment programs for the BSc(Pharm), PharmD, and Flexible PharmD programs

- Provided guidance on assessment practices to instructors in the BSc(Pharm) and PharmD programs

- Participated in the development of an integrated respirology module for the BSc(Pharm) program

- Organized Educators meetings for the Associate Dean Academic

- Organized the Faculty's annual curriculum retreat

- Provided a TA Training Program to 11 graduate students

2) Faculty development and career advancement (i.e., educational leadership opportunities; navigating tenure and promotion processes; documenting professional growth and impact)

- Organized Celebrate Learning Week presentations and workshop

- Organized a series of curriculum development workshops in spring 2015

- Hosted webinars on teaching and learning topics

- Prepared and distributed the weekly "OESD Bulletin" newsletter including a How To document on creating the newsletter

- Organized and delivered two New Faculty Orientation workshops

- Organized and delivered two Promotion and Tenure workshops

- Provided assistance with CV and teaching dossier preparation to colleagues

3) Program evaluation (i.e., student evaluations of teaching and peer reviews of teaching)

- Conducted 140 student evaluations of teaching and course evaluations

- Organized 17 peer reviews of teaching

- Administered the selection processes for the Killam Teaching Prize and the Faculty Teaching Awards

- Created How-To documents for both the evaluation and peer review of teaching processes

4) SoTL (i.e., nurturing the growth of educational scholars; creating context-specific evidence for curriculum decision-making; providing support for preparation and dissemination of scholarship)

- Gave three podium presentations at the 2014 AFPC-CPERC Conference

- Gave one podium presentation at the 2015 eHITS technology showcase

- Administered a SoTL mini-grant program, which distributed $\$ 4000$ in funding. A How To document was also prepared regarding administration of the program

- Conducted a comprehensive SoTL project to examine faculty and student perspectives regarding the respirology module

- Submitted abstract for 2015 STLHE conference (accepted for roundtable)

- Submitted five poster abstracts for 2015 AFPC-AACP conference (accepted)

- Submitted one manuscript for publication (under review)

- Mentored faculty members on preparation of TLEF grant applications, behavioural research ethics review applications, abstracts, posters, and manuscripts 


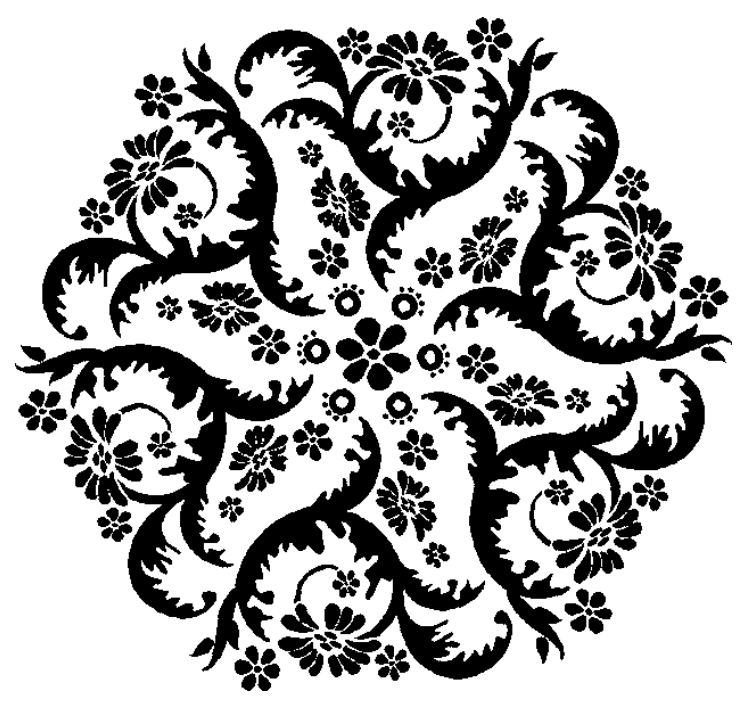

